\title{
Extreme Programming Study Method Case Study on Designing of Accounting Term Dictionary
}

\author{
Usman Ependi, Qoriani Widayati \\ Computer Science, Bina Darma University \\ ${ }^{1}$ usman@mail.binadarma.ac.id \\ 2 qoriani_widayati@mail.binadarma.ac.id \\ Jl. A. Yani No. 12 Plaju Palembang
}

\begin{abstract}
Extreme Programming (XP) is a software development method that is simple and includes one of the agile methods pioneered by Kent Beck, Ron Jeffries, and Ward Cunningham. The main purpose of the Extreme Programming method is to reduce the cost of software changes, in traditional systems development methodologies, system requirements specified in the first phase of the project development and it is not changed. This means that the cost to the needs of the change that occurs in the later stages will be very expensive. The Results of this study are to determine how the weaknesses and strengths of the XP method of making an application accounting terms dictionary on a Smartphone.
\end{abstract}

Keywords - XP, Accounting term, smartphone

\section{INTRODUCTION}

Agile Methods are developed for the traditional methodology, there are many things that make the development process can't be managed properly as the user desires. This methodology has been pretty much grown, they are:
1. Extreme Programming $(X P)$
2. Scrum Methodology
3. Crystal Family
4. Dynamic Systems Development Method (DSDM)
5. Adaptive Software Development (ASD)
6. Feature Driven Development (FDD)

Extreme Programming (XP) is a software development method that is simple and includes one of the agile methods pioneered by Kent Beck, Ron Jeffries, and Ward Cunningham. XP is one of the agile methods are the most widely used and became a very famous approach. The goals of XP is a team formed between small to medium sized course, not necessary to use a large team. It is intended to deal with unclear requirements and the change of requirements very quickly [1]

The main goal of XP is for a down the cost of a change Software.

In traditional systems development methodologies, system requirements specified in the early stages of project development and these permanent. This means that the cost of a change in requirements that happened to next stage will be an expensive. XP is directed for a lowering the cost of a change by introducing the basic values, principles and practical. By applying an XP, the development of a system must be more flexible to changes in

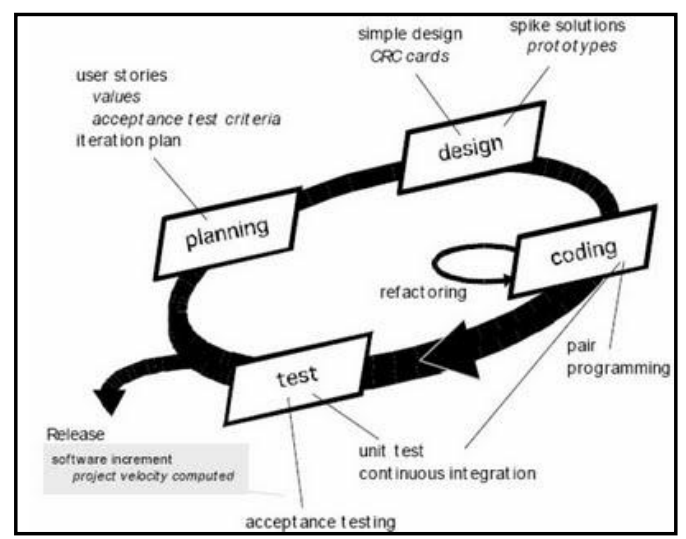

Fig1. Extreme Programming Process

\section{Materials AND Methods}

\subsection{Literature Review}

\subsubsection{Extreme Programming (XP)}

According to the Pressman [4] Extreme

Programming processes are:

\section{Planning}

This phase is started with listening is a collection activity requirements (needs) of a system that allows users of the technical team to understand the business context for a XP system and get a clear picture of the main features, functionality, and desired output. Listening leads to the creation of a collection of stories (usually also known as user stories) that describe the features, functionality, and the desired output for the system want to build.

2. Design

XP encourages the use of CRC cards (Class-

Responsibility-Collaborator), where the CRC cards are used to identifying and organizing objectoriented classes. CRC card is only to design a system that is generated as part of the XP process.

3. Coding

The key Concepts for coding activity is a pair programming. XP recommends two persons to work together to create a code in a story. This concept provides a mechanism for solving a 
problem in real time (two or more people better than themselves) and quality assurance in real time.

\section{Testing}

XP acceptance tests specified by the users of the system and focuses on the features and functionality of the overall visible and was reviewed by the users of the system. Acceptance tests originated of the user stories that have been implemented as part of the release system

\subsubsection{The Advantages of the XP Method}

The target Extreme Programming is a team formed between small to medium sized course, do not need to use a large team. It is intended to deal with unclear requirements and the requirements changes very quickly. Extreme Programming is an agile method the most widely used and became a very well-known approach.

$\mathrm{XP}$ is very minimum of documentation. This is accomplished to keep the agile methodology, because if it gets too much documentation (formal), then a software development methodology can no longer be classified in agile methods.

Every change or additional the functions and features can be delivered directly by outside the customer without having to make a formal letter which stated the request additions and changes. The developer can also respond instantly without having a formal statement, when it is also in accordance with the practice of collective ownership, although the currently a programmer may not be in place, the change or addition to the functions in the program code can be done by anyone who is ready.

\subsubsection{The weakness of the XP method}

1. Developers should always be ready to change because change is always appreciated.

2. Can not make a detailed code at the beginning (the principle of simplicity and also suggestions for doing what is necessary same day).

\subsection{Reseach Method}

The research method used in this research is descriptive method. Where is research descriptive study intended to describe the phenomena that exist, both natural phenomena and man-made phenomena. The phenomenon could be the shape, activity, characteristics, changes, relationships, similarities, and differences between one phenomenon with another phenomenon [2].

\subsection{Implementation of XP on the Accounting Terms}

\section{Dictionary}

1. Planning

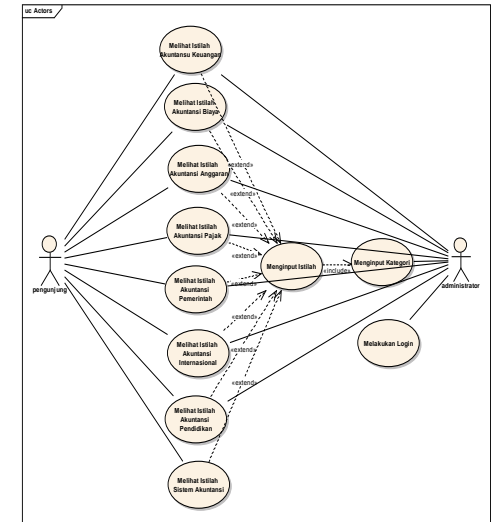

Fig. 2 Use Case Diagram

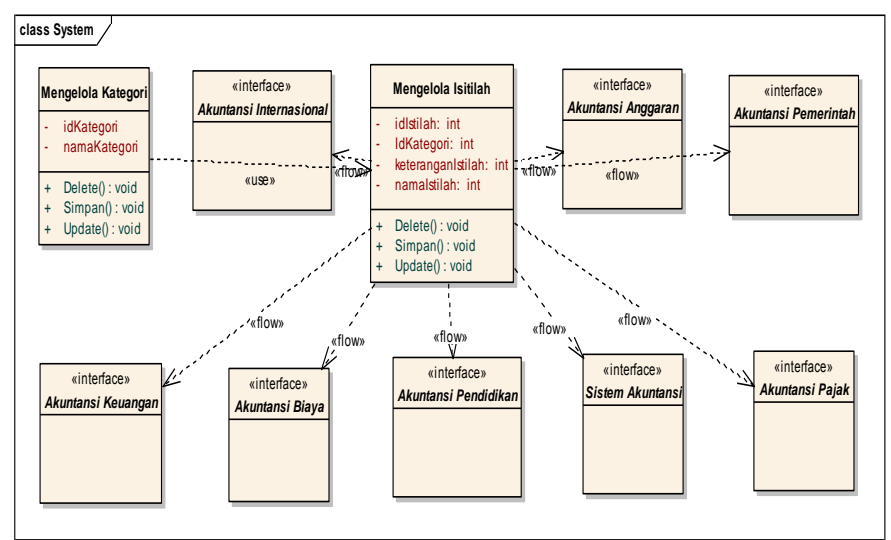

Fig 3. Class Diagram

2. Design

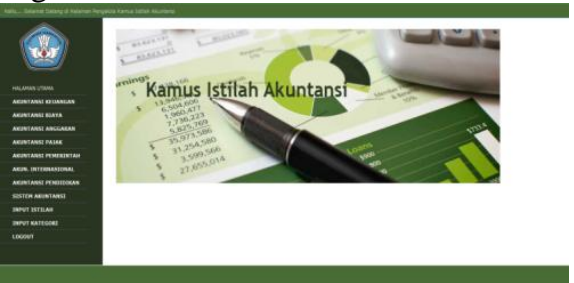

Fig 4. Home dministrator

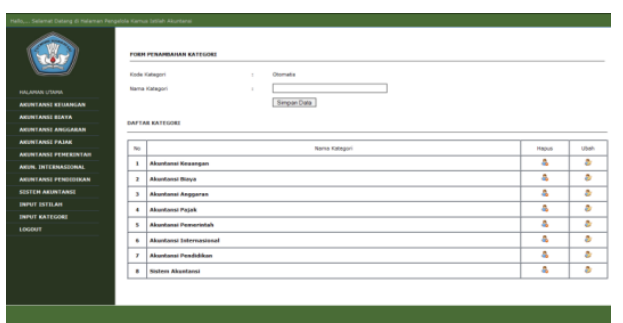

Fig 5. Input Category of Accounting Term 


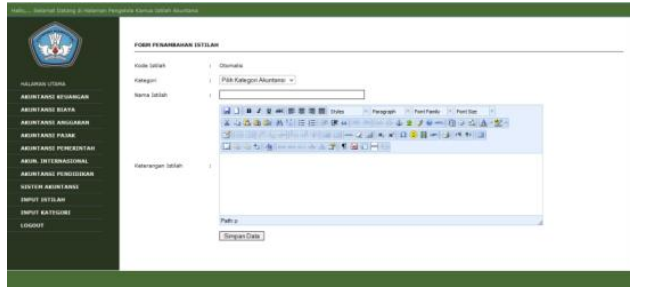

Fig 6. Input Page of Accounting Term
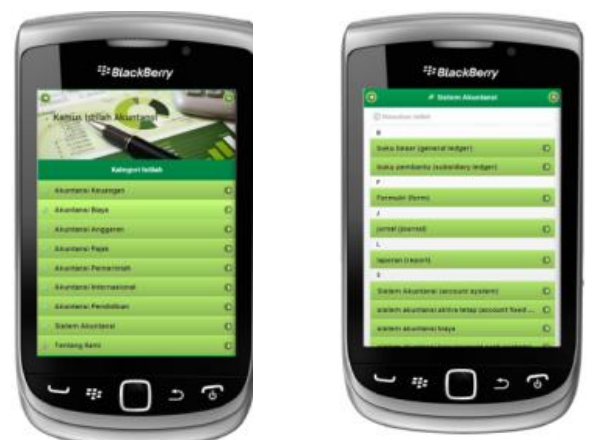

Fig 7. The main menu and Accounting Term

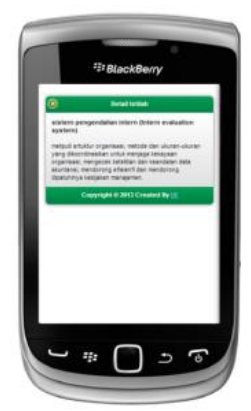

Fig 8. Accounting Term Detail page

\section{Coding}

After designing method done, then it will made the coding to make the program. Coding made with the PHP programming language.

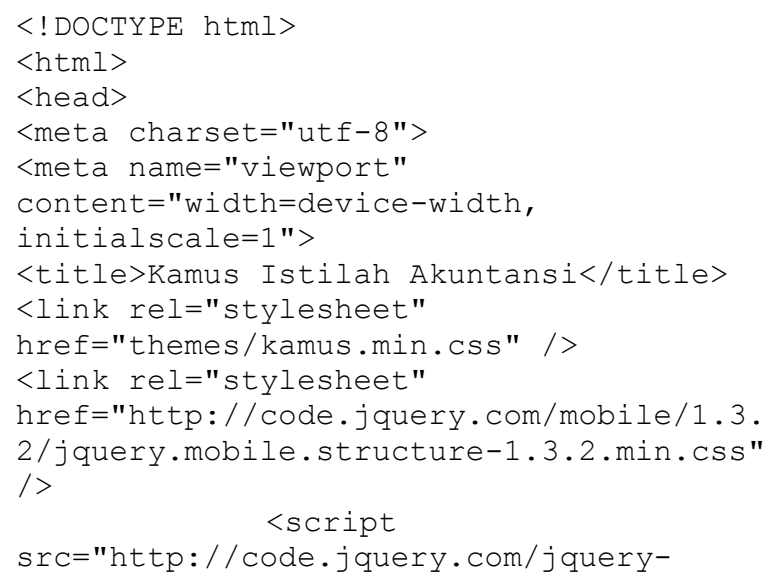

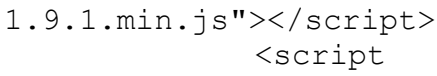

src="http://code.jquery.com/mobile/1.3.2 / jquery.mobile-1.3.2.min.js" $></$ script $>$

$</$ head $>$

$<$ body $>$

$<$ div data-role="page" data-

theme="a" $>$

$<$ div data-

role="header" data-

position="inline" $><$ img

src="images/banner.jpg" width="100\%"

class="ui-li-icon">

$<a$ href="index $\cdot p h p "$

data-icon="home" data-iconpos="notext"

data-direction="reverse" $>$ Home $</$ a $>$

$<a$ href="\#" data-

icon="search job vacancy" data-

iconpos="notext" data-rel="dialog" datatransition="fade" $>$ Cari Semua

Kategori</a>

$<$ h1 $>$ Kategori Istilah

$</$ h $1>$

$$
</ \text { div }>
$$

$<$ div data-role="content" data-theme="a"> $<$ ul data-role="listview">

$<$ li $><$ a data-ajax='false' href="\#" data-

transition="pop" $><$ img

src="images/money.png" class="ui-li-

icon" $>$ Akuntansi Keuangan $\langle/ a\rangle\langle/$ li $\rangle$

$<l i><a$ data-ajax='false' href="\#" data-

transition="pop" $><$ img

src="images/money.png" class="ui-li-

icon" $>$ Akuntansi Biaya $</ a></$ i $>$

$<$ li $><$ a data-ajax='false' href="\#" data-

transition="pop" $><$ img

src="images/money.png" class="ui-li-

icon" $>$ Akuntansi Anggaran $\langle/ a\rangle\langle/ 1 i\rangle$

$<$ li $><$ a data-ajax='false' href="\#" data-

transition="pop" $><$ img

src="images/money.png" class="ui-li-

icon" $>$ Akuntansi Pajak $</ a></ l i>$

$<$ i $><a$ data-ajax='false' href="\#" data-

transition="pop" $><$ img

src="images/money.png" class="ui-li-

icon" $>$ Akuntansi Pemerintah $\langle/ a\rangle\langle/ 1 i\rangle$

$<$ i $><a$ data-ajax='false' href="\#" data-

transition="pop" $><$ img

src="images/money.png" class="ui-li-

icon" $>$ Akuntansi Internasional $\langle/ a\rangle\langle/ 1 i\rangle$

$<l i><a$ data-ajax='false' href="\#" datatransition="pop" $><$ img

src="images/money.png" class="ui-li-

icon" $>$ Akuntansi Pendidikan $\langle/ a\rangle\langle/ 1 i\rangle$

$<$ li $><$ a data-ajax='false' href="\#" data-

transition="pop" $><$ img

src="images/money.png" class="ui-li-

icon" $>$ Sistem Akuntansi</a $></ 1 i>$

$<$ li $><$ a data-ajax='false' href="\#" data-

transition="pop" $><$ img

src="images/group.png" class="ui-li-

icon" Tentang Kami $</ a></ l i>$

$</$ ul $>$

$</$ div $>$

$<$ section $><$ footer data- 
role="footer" $><$ h2 $>$ Copyright $\odot 2013$

Created By $<$ a

href="http://blog.binadarma.ac.id/usman"

$>$ Usman $</$ a $></$ h $2>$

$</$ footer $>$

$</$ section $>$

$</$ div $>$

$</$ body $>$

$</$ html $>$

\section{Testing}

Software testing is meant to test all the elements that made the software is already in accordance with the expected. Software testing in this study using Black Box testing method. Black box testing is a fundamental aspect of software testing without considering internal logic structure of software. This method is used to find out whether the software is working properly. Here is one of the results of tests performed using the black box testing:

\section{Login testing}

TABLE 1

PENGUJIAN LOGIN

\begin{tabular}{|c|c|c|c|}
\hline Input & Expected & $\begin{array}{l}\text { observati } \\
\text { on }\end{array}$ & $\begin{array}{l}\text { conclus } \\
\text { ion }\end{array}$ \\
\hline \multicolumn{4}{|c|}{ Data (Correct) } \\
\hline $\begin{array}{l}\text { Username } \\
\text { holistic } \\
\text { Password } \\
\text { correct }\end{array}$ & $\begin{array}{l}\text { Showing page of } \\
\text { users based on } \\
\text { access }\end{array}$ & $\begin{array}{l}\text { Users based } \\
\text { on the access } \\
\text { page } \\
\text { displayed }\end{array}$ & Accepted \\
\hline \multicolumn{4}{|c|}{ Data (incorrect) } \\
\hline $\begin{array}{l}\text { Username } \\
\text { holistic } \\
\text { Password } \\
\text { incorrect }\end{array}$ & $\begin{array}{l}\text { Displays } \\
\text { messages } \\
\text { username or } \\
\text { password } \\
\text { incorrect }\end{array}$ & $\begin{array}{l}\text { Username or } \\
\text { password } \\
\text { incorrect } \\
\text { message } \\
\text { displayed }\end{array}$ & Accepted \\
\hline
\end{tabular}

2. Data input Testing Category

TABLE 2

DATA INPUT TESTING CATEGORY

\begin{tabular}{llll}
\hline Input & Expected & observation & conclusion \\
\hline $\begin{array}{l}\text { Input } \\
\text { data }\end{array}$ & $\begin{array}{l}\text { The data can be } \\
\text { saved into the } \\
\text { database }\end{array}$ & $\begin{array}{l}\text { The data } \\
\text { storage can } \\
\text { be done }\end{array}$ & Accepted \\
\hline $\begin{array}{l}\text { Update } \\
\text { data }\end{array}$ & $\begin{array}{l}\text { Data can be } \\
\text { converted into the } \\
\text { database }\end{array}$ & $\begin{array}{l}\text { The data } \\
\text { changes can } \\
\text { be }\end{array}$ & Accepted \\
& performed & \\
\hline $\begin{array}{l}\text { Delete } \\
\text { Data }\end{array}$ & $\begin{array}{l}\text { The data can be } \\
\text { deleted from the } \\
\text { database }\end{array}$ & $\begin{array}{l}\text { The } \\
\text { Elimination } \\
\text { of data can } \\
\text { be done }\end{array}$ & \\
& & Accepted & \\
& & &
\end{tabular}

\section{CONCLUSIONS}

The results of this research that XP has some strengths and weaknesses, the Additional advantages of XP Establish good communication with clients, Lowering the cost of development, Improving Communication and the nature of each respect among developers, the Additional weaknesses while XP cannot make a detailed code at the beginning.

\section{REFERENCES}

1. Widodo, Massus Subekti. 2006. Requirements Management Pada Extreme Programming. Seminar Nasional Aplikasi Teknologi Informasi.Yogyakarta2.

2. Sukmadinata, Syaodih Nana. 2006,Metode Penelitian Pendidikan. Bandung, Remaja Rosdakarya

3. Widodo, Massus Subekti. 2006. Requirements Management Pada Extreme Programming. Seminar Nasional Aplikasi Teknologi Informasi.Yogyakarta

4. Pressman S Roger. 2010. Software Engineering: A Practitioner's Approach (7thEd). Mc Graw-Hill. New York

5. Michalewicz, Z.: Genetic Algorithms + Data Structures = Evolution Programs. 3rd edn. Springer-Verlag, Berlin Heidelberg New York (1996) 